\title{
Urgences
}

\section{En face du rond-point...}

\section{Mireille Goulet}

Numéro 13, mars 1986

\section{Éclats d'atelier}

URI : https://id.erudit.org/iderudit/025226ar

DOI : https://doi.org/10.7202/025226ar

Aller au sommaire du numéro

Éditeur(s)

Urgences

ISSN

0226-9554 (imprimé)

1927-3924 (numérique)

Découvrir la revue

Citer ce document

Goulet, M. (1986). En face du rond-point... Urgences, (13), 59-60.

https://doi.org/10.7202/025226ar

Ce document est protégé par la loi sur le droit d'auteur. L'utilisation des services d'Érudit (y compris la reproduction) est assujettie à sa politique d'utilisation que vous pouvez consulter en ligne.

https://apropos.erudit.org/fr/usagers/politique-dutilisation/
Cet article est diffusé et préservé par Érudit.

Érudit est un consortium interuniversitaire sans but lucratif composé de l’Université de Montréal, l'Université Laval et l'Université du Québec à Montréal. Il a pour mission la promotion et la valorisation de la recherche. https://www.erudit.org/fr/ 


\section{Mireille Goulet}

En face du rond-point où aboutissent les avenues Seurat et Signac, habite $M$. Poincaré, membre illustre de l'école du pointillisme linguistique. Si quelqu'un peut me donner la réponse à la question que m'a posée Derna Vergasi, c'est bien lui.

Je suis sur le point de frapper à sa porte lorsque, d'elle-même, elle s'ouvre toute grande. Ce qui fait que mon poing heurte ce qui, en principe, doit être le visage de $M$. Poincaré. Je suis gênée à un point tel que je ne bouge ni ne dis quoi que ce soit. Je ne peux que fixer des cheveux qui pointent comme s'ils étaient aspirés par le haut, deux billes hors de leurs orbites, un nez sanguinolent qui semble vraiment mal en point et une bouche qui ne tarit point d'exclamations incompréhensibles mais qui réussit tout de même à retenir un pinceau maculé de rouge. Ouf! je respire, ce n'est donc pas du sang qui tache mon poing et le visage de mon vis-à-vis. Je suis sur le point de repartir quand, autour du pinceau, je vois poindre un sourire qui ne peut s'adresser qu'à moi. Profitons-en!

\section{- Vous êtes bien M. Poincaré?}

- Sur ce point, il n'y a aucun doute. Et vous êtes sûrement celle qui ce matin me téléphonait pour prendre rendez-vous.

- C'est bien moi en effet.

- Entrez donc!

Aux quatre points cardinaux de la pièce où je pénètre, trônent des sphères auxquelles des pointes de javelots servent de point d'appui. Au centre, une sphère encore plus grosse, en point d'équilibre sur une aiguille. Sa position inusitée et son éclat en font sans contredit le point de mire de cette pièce. Tout autour de cette énorme boule sont disposés des coussins ronds, brodés au point de croix. Du doigt, $M$. Poincaré me désigne celui sur lequel il m'invite à prendre place. Je me 
dirige dans la direction opposée, un claquement de langue m'arrête. - Ne m'en veuillez pas, c'est que sur ce point, je suis très pointilleux. Je n'insiste pas et m'assois sur le coussin.

- Vous savez, je me fait un point d'honneur de vous satisfaire en tout point. Mais commençons donc par le point de départ. N'aviezvous point d'interrogations à me faire?

- C'est même la raison qui m'amène, M. Poincaré!

- Les questions qui n'ont pas obtenu de réponse sont mon point faible! Racontez tout, puisque nous sommes à un point de non-retour. - Voilà, je veux savoir quel est le plus long chemin d'un point à un autre.

- Avant de vous donner mon point de vue, je dois vous dire que ce problème m'intéresse au plus haut point. À vrai dire, il vient à point car je commençais à tourner en rond, à m'ennuyer à un point tel que j'avais presque atteint le point critique. Vous voyez que vous arrivez à point nommél

- Si cela ne vous dérange pas trop, j'aimerais avoir une réponse avant le point du jour... Sans vouloir mettre les points sur les i, je vous fais remarquer à quel point je suis pressée. Derna Vergasi veut une réponse, un point c'est tout!

- Eh bien! puisque vous semblez être rendue au point d'ébullition, vous direz à Derna Vergasi que la distance la plus longue entre deux points est un autre point: le point de fuite. 